\title{
Effects of exposure to extremely low-frequency electromagnetic fields on the differentiation of Th17 $\mathrm{T}$ cells and regulatory $\mathrm{T}$ cells
}

\author{
Yun-Jung Lee ${ }^{1 \star}$, Kyeong Eun Hyung ${ }^{1 \star}$, Jong-Sun Yoo ${ }^{1}$, Ye Won Jang ${ }^{1}$, Soo Jeong Kim ${ }^{1}$, Do Ik \\ Lee $^{2}$, Sang Joon Lee ${ }^{2}$, So-young Park ${ }^{3}$, Ji Hoon Jeong ${ }^{4}$ and Kwang Woo Hwang ${ }^{1}$ \\ ${ }^{1}$ Laboratory of Host Defense Modulation, College of Pharmacy, Chung-Ang University, Seoul 06974, Korea \\ ${ }^{2}$ College of Pharmacy, Chung-Ang University, Seoul 06974, Korea \\ ${ }^{3}$ Laboratory of Pharmacognosy, College of Pharmacy, Dankook University, Cheonan 31116, Korea \\ ${ }^{4}$ Department of Pharmacology, College of Medicine, Chung-Ang University, Seoul 06974, Korea
}

\begin{abstract}
The potential risks that electromagnetic fields (EMF) pose to human physiology have been debated for several decades, especially considering that EMF is almost omnipresent and some occupations involve regular exposure to particularly strong fields. In the present study, the effects of $60 \mathrm{~Hz}$ $0.3 \mathrm{mT}$ EMF on $\mathrm{CD}^{+}{ }^{+} \mathrm{T}$ cells were evaluated. Production of T cell related cytokines, IFN- $\gamma$ and IL-2, was not altered in $\mathrm{CD} 4^{+} \mathrm{T}$ cells that were exposed to EMF, and cell proliferation was also unaffected. The expression of genes present in a subset of Th17 cells was upregulated following EMF exposure, and the production of effector cytokines of the IL-17A subset also increased. To determine signaling pathways that underlie these effects, phosphorylation of STAT3 and SMAD3, downstream molecules of cytokines critical for Th17 induction, was analyzed. Increased SMAD3 phosphorylation level in cells exposed to EMF, suggesting that SMAD3 may be at least in part causing the increased Th17 cell production. Differentiation of Treg, another $\mathrm{CD} 4^{+} \mathrm{T}$ cell subset induced by SMAD3 signaling, was also elevated following EMF exposure. These results suggest that $60 \mathrm{~Hz} 0.3 \mathrm{mT}$ EMF exposure amplifies TGF- $\beta$ signaling and increases the generation of specific $T$ cell subsets.
\end{abstract}

Key words: EMF - SMAD $3-$ TGF- $\beta-$ Th17 - Treg

\section{Introduction}

The biological effects of low frequency electromagnetic fields (EMF) have been the subject of substantial scientific debates for the past several decades. The topic is under public scrutiny as it is a considerable environmental issue, with nearly all of civilized world being exposed to some forms of EMF from either natural or artificial sources. A study in France showed that occupational and residential exposure to EMF might play a role in the occurrence of meningioma (Baldi et al. 2011). Another study in Sweden assessed the potential dangers of exposure to EMF, and suggested a possible relationship between parental occupational exposure to

*These authors contributed equally to this work.

Correspondence to: Kwang Woo Hwang, Laboratory of Host Defense Modulation, College of Pharmacy, Chung-Ang University, 221 Heukseok-dong, Dongjak-gu, Seoul 06974, Korea

E-mail:khwang@cau.ac.kr
EMF and the incidence of leukemia (Feychting et al. 2000). However, another study has also reported that there is no association between occupational exposure to magnetic fields and risks of leukemia and other cancers (Johansen et al. 2007).

The effects of magnetic fields on immune cells, especially $\mathrm{T}$ cells, have been studied in the past, albeit utilizing a much powerful EMF than the one employed in the present study. Some of the earlier studies have shown that EMF exposure does not affect the viability of various immune cells (Norimura et al. 1993), while other research has described the impact of $50 \mathrm{~Hz}$ EMF on in vitro T lymphocyte adherence (Cocek et al. 2012). This current study focused on observing changes in $\mathrm{T}$ cell functionality under exposure to $60 \mathrm{~Hz} 0.3 \mathrm{mT}$ EMF.

In order for the body's adaptive immune system to effectively combat pathogens, lymphocytes must be differentiated into the appropriate effector types for each challenge. Under the guidance of the innate immune system, $\mathrm{CD} 4^{+}$ 
helper T cells differentiate into various types in the peripheral tissues in order to elicit an effective immune response (Paul et al. 1994). Two helper subsets that have received considerable attention in the past are T helper type 1 cells (Th1), which produce the cytokine interferon- $\gamma$ (IFN- $\gamma$ ) and Th2 cells, which produce IL-4, IL-5, and IL-13 (Abbas et al. 1996; Glimcher et al. 2000). While these helper subsets are designed to fight off pathogens, Th1 cells have also been implicated in various autoimmune diseases when their functions are misdirected (Trembleau et al. 1995; Gately et al. 1998). However, in recent years it has been recognized that Th1 cells may not be the sole effector behind autoimmune diseases. It was found that autoimmune models such as collagen-induced arthritis (CIA) and experimental autoimmune encephalomyelitis (EAE) are exacerbated in the absence of Th1-specific cytokines (Chen et al. 2006; Iwakura et al. 2006). This led to the identification of another subset of helper T cells, which was named Th17 as they produce the cytokine IL-17. These cells function independently of STAT1 or T-bet, secrete IL-17A and IL-17F, are induced by IL- 6 and TGF- $\beta$, and are maintained by IL-23 (Aggarwal et al. 2003; Harrington et al. 2005; Park et al. 2005; Iwakura et al. 2006; McKenzie et al. 2006).

Another cell type that plays a pivotal role in immune homeostasis by suppressing excessive immune responses is regulatory T cells (Treg). These cells were discovered in the early 1970's (Gershon et al. 1971), and subsequent studies have demonstrated that the transcription factor forkhead box P3 (Foxp3) is a key factor in regulatory T cell development as well as being a key phenotypic marker of these cells (Hori et al. 2003; O'Garra et al. 2003). The fact Treg cells play an important role in the maintenance of peripheral tolerance is demonstrated by the severe autoimmune response that occurs in patients afflicted with IPEX syndrome, which is characterized by a lack of Foxp3 expression (Bennett et al. 2001). The induction of these cells from naïve T cells in vitro can be achieved by providing TCR stimulation along with transforming growth factor (TGF- $\beta$ ) and interleukin-2 (IL-2) (Chen et al. 2003). It is important to note that both Th17 cells and Treg cells require TGF- $\beta$ for their differentiation.

In the current study, the effects of extremely low frequency EMF on $\mathrm{CD}^{+}{ }^{+} \mathrm{T}$ cells were observed, with a specific focus on the Th17 and regulatory $\mathrm{T}$ cell subsets.

\section{Materials and Methods}

\section{Electromagnetic field exposure system}

The equipment for EMF generation was designed and constructed by Electrotechnology Research Institute (Dankook University, Kyunggi-Do, Korea). Magnetic field monitoring was conducted by monitoring of the field strength with a handheld tesla meter (Kanetec, Japan). In order to display uniform EMF in commercially available incubators, the interior space of commercially available incubators was shielded using an $80 \%$ nickel mu-metal chamber fitted into the incubator. The mu-metal chamber was ventilated at the upper and lower corners via $2.0 \mathrm{~cm}$ diameter holes that have $2.0 \mathrm{~cm}$ extension tubes to prevent the entry of stray EMF (Fig. 1A).

The field generator comprised 4 square coils and one cage with three testing floors (top, middle, and bottom floors). The $60 \mathrm{~Hz}$ EMF was produced by one pair of Helmholtz coils with windings embedded in an open wooden rectangular frame. Each coil had 200 turns of an insulated soft copper wire with a diameter of $1.0 \mathrm{~mm}$, and was connected in series
A

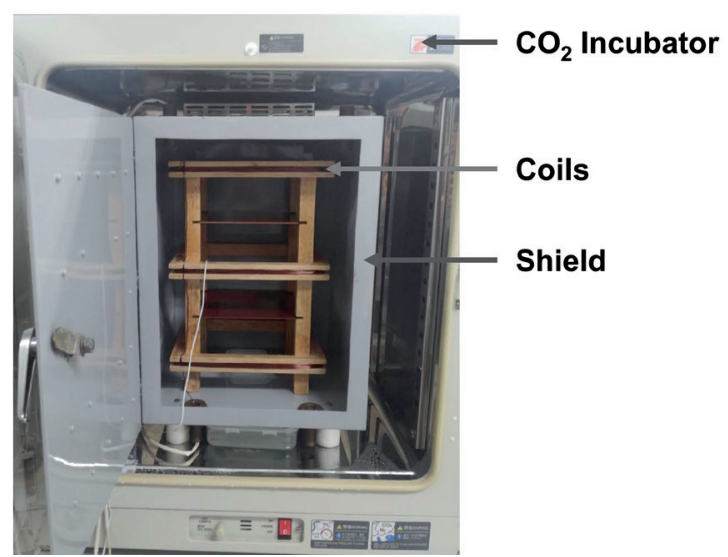

B

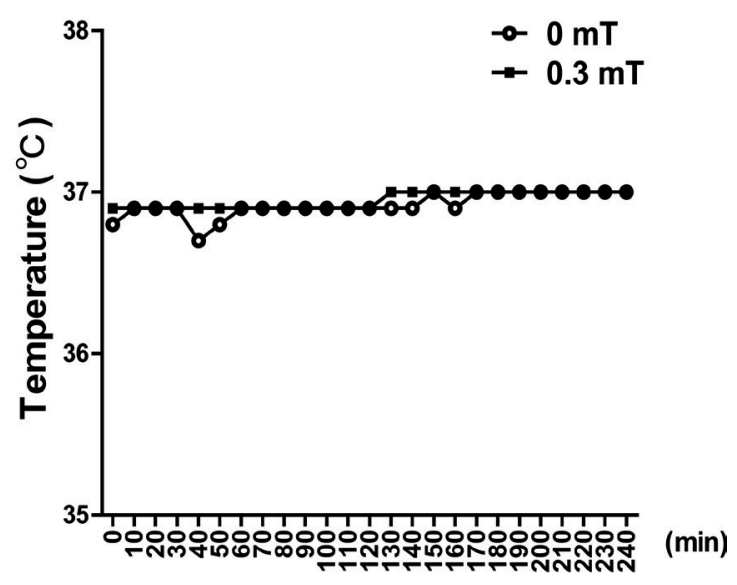

Figure 1. The $60 \mathrm{~Hz} 0.3 \mathrm{mT}$ electromagnetic field exposure system used for in vitro studies. A. EMF exposure system consisting of magnetic generating coils and a ferrite shielding system in a $\mathrm{CO}_{2}$ incubator. B. Maintenance of temperature in the exposure location. 
to a $220 \mathrm{~V}$ AC power supply via a transformer. Each winding was split, allowing the current to flow in the same direction through each half of the winding (field adding). We were able to control the intensity of the EMF using the transformer. The EMF at the center of the middle floor was fixed at $0.3 \mathrm{mT}$, and the fields at various points were measured to determine the uniformity of the EMF exposure system. The spatial variation of the magnetic field was $<3 \%$, strongly demonstrating that the field generator was applicable for an in vitro study within a small area. The temperature in the incubator at $0.3 \mathrm{mT}$ was maintained at $37 \pm 0.3^{\circ} \mathrm{C}$ during the experimental period (Fig. 1B). Compared with the magnitude of the magnetic fields generated by the exposure system, the magnitude of the AC background fields, which is usually negligible, and the DC background fields were equal to the Earth's magnetic field.

\section{Mice}

Six-week-old male C57/BL6 mice were purchased from Orient Bio (Gyeonggi-do, Korea) and housed under specific pathogen-free (SPF) conditions with temperature control at $24 \pm 2^{\circ} \mathrm{C}$ and 12 hour 12 hour light-dark cycle throughout the entire experiment. Mice were given standard laboratory grade food and water prior to experiments. After a week of stabilization, mice were sacrificed and the spleen was extracted. All experimental procedures were conducted in accordance with the National Institutes of Health Guide for the care and use of laboratory animals and approved by the Chung-Ang University's Institutional Animal Care and Use Committee (IACUC number: 14-0033). Six-week-old male Foxp3-GFP mice, that express GFP knocked into the Foxp3 locus, were utilized in this study. The Foxp3-GFP mice were a gift from Dr. Rudensky (Howard Hughes Medical Institute, Memorial Sloan-Kettering Cancer Center, NY, USA).

\section{Reagents}

PE-conjugated IL-17A antibodies and the protein transport inhibitor Golgiplug were purchased from Ebioscience (CA, USA). Anti-IL-2 and IFN- $\gamma$ capture and detection antibodies for ELISA were purchased from BD Bioscience (NJ, USA). Anti-CD4 Microbeads (L3T4), MiniMACS column and MACS multi stand were purchased from Miltenyi Biotec (Bergisch Gladbach, Germany).

\section{Purification of $C D 4^{+} T$ cells and cell culture}

After extraction of the spleen, the organ was prepared to obtain a single-cell suspension of splenocytes. Cells were purified using bead-antibody conjugates that bind to $\mathrm{CD} 4^{+}$ T cells using the MACS $^{\circledR}$ cell separation system (Miltenyi Biotec). Cells were cultured in RPMI-1640 medium containing $10 \%$ heat-inactivated fetal bovine serum, $100 \mathrm{U} / \mathrm{ml}$ penicillin and $100 \mu \mathrm{g} / \mathrm{ml}$ streptomycin at $37^{\circ} \mathrm{C}$ with $5 \% \mathrm{CO}_{2}$. For Th17 induction, cells were cultured in the presence of IL-6 (25 ng/ $\mathrm{ml})$ and TGF- $\beta$ (2.5 ng/ml). IL-2 (10 ng/ml) and TGF- $\beta$ $(2.5 \mathrm{ng} / \mathrm{ml})$ for the induction of regulatory $\mathrm{T}$ cell profiles were treated to $\mathrm{CD} 4^{+} \mathrm{T}$ cells. All T cells were given anti-CD3 and anti-CD28 stimulation.

\section{Enzyme-linked immunosorbent assay (ELISA)}

Plates (96-well) were coated overnight at $4^{\circ} \mathrm{C}$ with the capture antibody. Each well was washed three times with PBS-T, incubated for 1 hour with blocking solution at room temperature, and then washed four times with PBS-T. Samples and diluted standards were added to the plate and incubated overnight at $4^{\circ} \mathrm{C}$. After four wash cycles, the detection antibody was added. After 45-minute incubation at room temperature, the wells were washed and avidin-conjugated alkaline phosphatase was added at room temperature and incubated for 30 minutes. The substrate solution was then added and the plates were maintained at room temperature for 5 to 30 minutes before the addition of stop buffer. The absorbance was read at $405 \mathrm{~nm}$ using a microplate reader (Emax, Molecular Devices).

\section{Total RNA isolation and quantitative real-time RT-PCR}

Total RNA was isolated from each sample using TRIzol (Life Technologies, CA, USA). RNA was transcribed at $42^{\circ} \mathrm{C}$ for 1 hour in a volume of $25 \mu \mathrm{l}$ containing $5 \mathrm{x}$ RT buffer, $10 \mathrm{mM}$ dNTPs, Maloney murine leukemia virus reverse transcriptase and 100 pmol of oligo-dT primer. cDNA from each sample was amplified with $10 \mathrm{pmol}$ of each oligonucleotide primer, $0.2 \mathrm{mM}$ dNTPs, 1 unit of iTaq Plus DNA polymerase (iNtRON biotechnology, Gyeonggi-do, Korea) to a final volume of 20 $\mu$ l. cDNA was amplified by real-time PCR using SYBR Premix Ex Taq (Tli RNaseH Plus) (Takara; Shiga, Japan) in a CFX96 Real-Time PCR Detection System (Bio-Rad). To confirm the PCR specificity, PCR products were subjected to a meltingcurve analysis. The comparative threshold method was used to calculate the relative amount of mRNA in experimental samples compared to control samples. The number of amplification cycles was optimized in preliminary experiments to ensure that the reaction did not reach its plateau.

\section{Carboxyfluorescein diacetate succinimidyl ester (CFSE) proliferation analysis}

For cell proliferation analysis, $\mathrm{CD} 4^{+} \mathrm{T}$ cells enriched by negative selection were labeled with CFSE. Briefly, $5 \times 10^{6}$ cells were washed once and resuspended in PBS at a concentration of $2 \times$ $10^{7} / \mathrm{ml}$. An equal volume of a CFSE (Enzo Life Sciences, NY, USA) solution ( $5 \mu \mathrm{M}$ in PBS) was added and cells were incubated at room temperature for 10 minutes. The reaction was 
quenched by the addition of $5 \mathrm{ml}$ of cold medium for 1 minute. Cells were then washed twice in complete medium and cultured with or without EMF exposure. Cells were given anti-CD3 and anti-CD28 antibodies for stimulation and cultured for 72 hours. After harvesting, the cells were washed with PBS and analyzed by FACSCalibur and CellQuest analysis software. As a control group, stained cells were arrested using mitomycin C.

\section{Intracellular staining for cytokines}

For intracellular staining of cytokines, $\mathrm{CD} 4^{+} \mathrm{T}$ cells were isolated by magnetic cell sorting from splenocytes and cultured for 72 hours in the presence of Th17-driving conditions. After 72 hours, cells were re-stimulated using PMA and ionomycin along with a protein transport inhibitor for 6 hours. Cells were then fixed and stained using a Cytofix/ Cytoperm intracellular staining kit (BD Biosciences), according to manufacturer protocols. Stained cells were analyzed using a flow cytometer, FACSCalibur, and CellQuest analysis software (BD Biosciences).

\section{Western blot}

Whole cell proteins were extracted using RIPA buffer (Elpis Biotech, Daejeon, Korea). The extracts were separated by SDS-PAGE and transferred to a PVDF membrane. Blots were blocked and incubated at $4^{\circ} \mathrm{C}$ overnight with anti-actin (Stressgen, Victoria, Canada), anti-SMAD2,3, anti-phospho-SMAD-3 (Cell Signaling, MA, USA), anti-STAT3 or anti-phospho-STAT3 antibodies (Santa Cruz Biotechnology, California, USA). The membranes were then incubated with anti-mouse IgG or anti-rabbit IgG HRP-linked antibodies (Cell Signaling), and developed using ChemiGlow West (Alpha Innotech, CA, USA). Membranes were visualized using a ChemiDoc system (Bio-Rad).

\section{Statistical analysis}

Data are expressed as mean $\pm \mathrm{SD}$, and statistical analysis was performed using the Student's $t$ test.

\section{Results}

Exposure to $60 \mathrm{~Hz} 0.3 \mathrm{mT}$ EMF does not affect the production of inflammatory mediators and proliferation in $\mathrm{CD}^{+} \mathrm{T}$ cells

In order to gauge the effects of low-frequency EMF on immune cells, mouse $\mathrm{CD} 4^{+} \mathrm{T}$ cells were isolated from splenocytes to observe the production of key inflammatory mediators and $\mathrm{T}$ cell related cytokines. It was found that exposure to EMF $(0.3 \mathrm{mT})$ does not affect the production of IL-2 (0 mT: $26.3 \pm 2.9, n=3 ; 0.3 \mathrm{mT}: 26.2 \pm 1.2, n=3)$ and interferon-gamma (IFN- $\gamma)(0 \mathrm{mT}: 358.8 \pm 11.4, n=3$; $0.3 \mathrm{mT}: 369.8 \pm 25.8, n=3)$, which are cytokines produced by the Th1 cell subset (Fig. 2A).

As Th1 cell specific cytokines were shown to be unaffected by exposure to EMF, $\mathrm{CD} 4^{+}$T cells were isolated and cultured to measure their proliferative activity. Isolated $\mathrm{CD} 4^{+} \mathrm{T}$ cells were stained with CFSE and cultured with or without EMF exposure. Cells were harvested and analyzed using flow cytometry, and it was found that exposure to EMF did not significantly affect the proliferation of $\mathrm{T}$ cells compared to a control group that was treated with mitomycin C (Fig. 2B).

$m R N A$ levels and cytokine production of essential factors for the Th17 subset are increased following exposure to $60 \mathrm{~Hz}$ $0.3 \mathrm{mT}$ EMF

As there were no differences in Th1 cytokine production or $\mathrm{T}$ cell proliferation between exposed and unexposed groups,

\section{A}
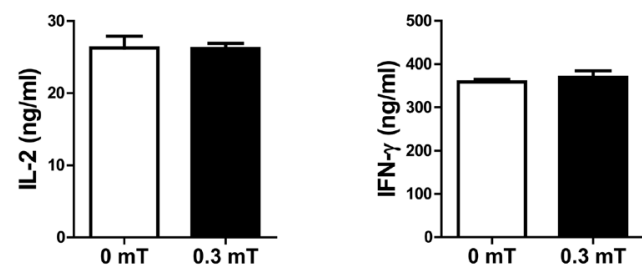

B

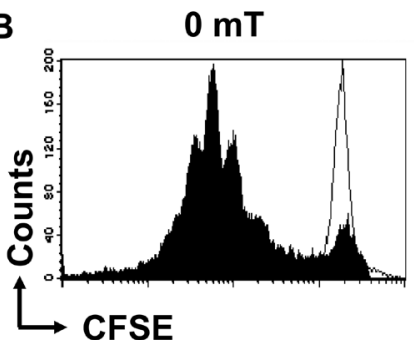

$0.3 \mathrm{mT}$

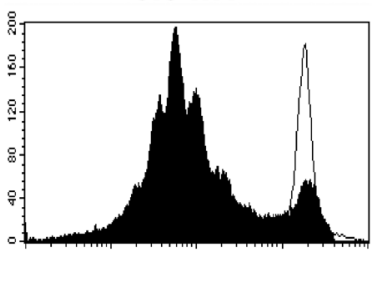

Figure 2. Exposure to $60 \mathrm{~Hz} 0.3 \mathrm{mT}$ electromagnetic fields decreases production of IL- 2 and IFN- $\gamma$ but T cell proliferation is not significantly affected. A. CD ${ }^{+}$T cells were isolated from mouse splenocytes and cultured in the presence of anti-CD3 and anti-CD28 antibodies $(1 \mu \mathrm{g} / \mathrm{ml}$ each) for 16 hours with or without EMF exposure $(0.3 \mathrm{mT})$. The white bar denotes the control group while the black bar represents the EMF exposed group. The supernatant was harvested for analysis using enzyme-linked immunosorbent assay (ELISA). Production of IL-2 and IFN- $\gamma$ was not affected by EMF exposure. B. $\mathrm{CD} 4^{+} \mathrm{T}$ cells were isolated from mouse splenocytes and stained with CFSE before being cultured for 72 hours with or without EMF exposure. Cells were harvested and analyzed using flow cytometry. All cells were stimulated using anti-CD3 and anti-CD28 antibodies ( $1 \mu \mathrm{g} / \mathrm{ml}$ each). The filled histogram represents CFSE signals from cultured cells, while the open histogram represents CFSE-stained cells that were arrested by mitomycin $\mathrm{C}$ treatment at $0 \mathrm{~h}$. Data are representative of three experiments. 
we focused on other $\mathrm{T}$ helper cell subsets. $\mathrm{CD} 4^{+} \mathrm{T}$ cells were cultured under conditions that induce Th17 subset differentiation, and these cells were then cultured either with or without EMF exposure. It was found that the mRNA expression of IL-17A (2.3 folds, $2.3 \pm 0.1, n=3)$ and IL-17F (1.8 folds, $1.8 \pm 0.2, n=3$ ), effector cytokines for the Th17 subset, were significantly increased, along with genes for ROR $\gamma \mathrm{t}$ (1.7 folds, $1.7 \pm 0.1, n=3$ ), after exposure to EMF, as compared to mRNA levels in cells not exposed to EMF. However, the expression of IL-23R, a molecule that plays a role in Th17 lineage stabilization, was not significantly affected by exposure to EMF (1.1 folds, $1.1 \pm 0.2, n=3$ ) (Fig. 3A).

Next, the effect of EMF on the production of effector cytokines in the Th17 subset was observed by flow cytometry. $\mathrm{CD} 4^{+}$cells were isolated from mouse splenocytes and cultured in the presence of Th17-driving conditions either in the EMF exposure system or in a normal incubator. Cells were stained for IL-17A after being cultured for 72 hours (Fig. 3B). Production of IL-17A was increased by 2.4 folds in cells exposed to the EMF ( $31.57 \pm 2.2, n=3)$, as compared to the cells not exposed to the $\operatorname{EMF}(12.92 \pm 2.8, n=3)$.

\section{Phosphorylation of SMAD3, a crucial downstream target of} the TGF- $\beta$ signaling pathway, is increased under exposure to $E M F$

To investigate the signaling pathways involved in this apparent increase in Th17 effector cytokines, difference in phosphorylation levels of relevant signaling molecules were measured. As IL- 6 and TGF- $\beta$ are known to be required for Th17 subset development, the phosphorylation of the downstream molecules STAT3 and SMAD3, respectively, was assessed using western blot (Fig. 4A and B). It was found that the phosphorylation of SMAD3, a downstream target of TGF- $\beta$, was increased in cells exposed to EMF. Relative phosphorylation level of SMAD3/SMAD3 was increased by 1.3 folds in cells exposed to EMF $(1.8 \pm 0.2, n=3)$, as compared to cells not exposed to EMF $(1.5 \pm 0.1, n=3)$. The phosphorylation level of STAT3 was not significantly different between groups.

\section{Differentiation of regulatory $T$ cells is increased following EMF exposure}

Having shown that phosphorylation of SMAD3, a downstream signaling molecule of TGF- $\beta$, was increased under EMF exposure, regulatory $\mathrm{T}$ cell differentiation was assessed, as these cells require TGF- $\beta$ for their differentiation. $\mathrm{CD} 4^{+} \mathrm{T}$ cells were cultured under conditions that induce Treg subset differentiation, and those cells were then cultured with or without EMF exposure. It was found that the mRNA expression of TGF- $\beta$, an effector cytokine for the Treg subset, was increased ( 1.3 folds, $1.3 \pm 0.1, n=3$ ), as were mRNA levels for Foxp3 (1.2 folds, $1.2 \pm 0.1, n=3$ ), under exposure to EMF, as compared to mRNA levels in cells not exposed to EMF (Fig. 5A). To confirm that the same effect was seen on protein levels, the expression of Foxp3, a vital transcription factor for regulatory $\mathrm{T}$ cells, was
A
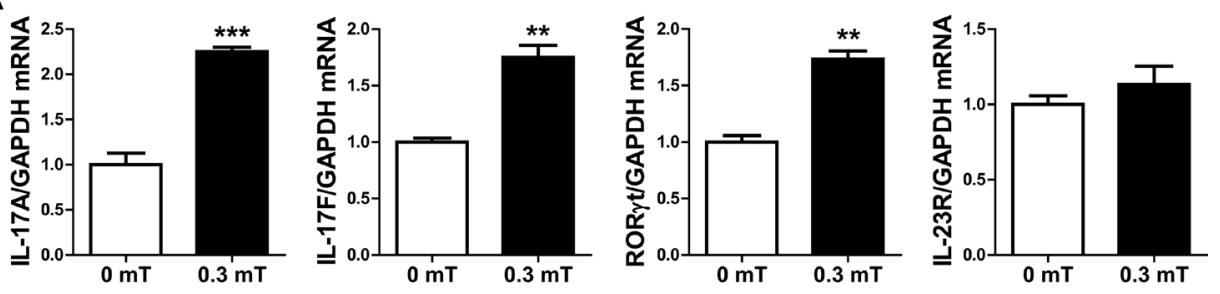

B

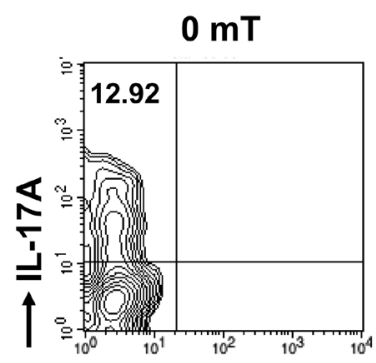

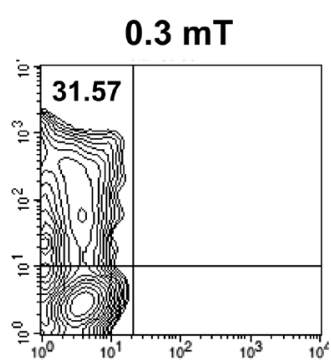

Figure 3. Increased expression of critical genes and cytokines of the Th17 cell lineage after exposure to $60 \mathrm{~Hz} 0.3 \mathrm{mT}$ EMF. A. CD4 ${ }^{+}$ $\mathrm{T}$ cells were isolated from mouse splenocytes and cultured in the presence of Th17-driving conditions, with or without EMF exposure, while being stimulated by anti-CD3 and anti-CD28 antibodies. The white bar denotes the control group while the black bar represents the EMF exposed group. Total RNA was extracted and reverse-transcribed for quantitative real-time PCR analysis with appropriate primers. Asterisks denote significance compared to control. ${ }^{* *} p<0.01 ;{ }^{* *} p<0.001$. B. $\mathrm{CD} 4^{+}$cells purified from mouse

splenocytes were stimulated by anti-CD3 and anti-CD28 antibodies and cultured under Th17-driving conditions, with or without EMF. Cells were fixed and stained for IL-17A expression 72 hours after being treated with PMA, ionomycin and brefeldin A, and assessed by flow cytometry. Data are representative of three experiments. 
A

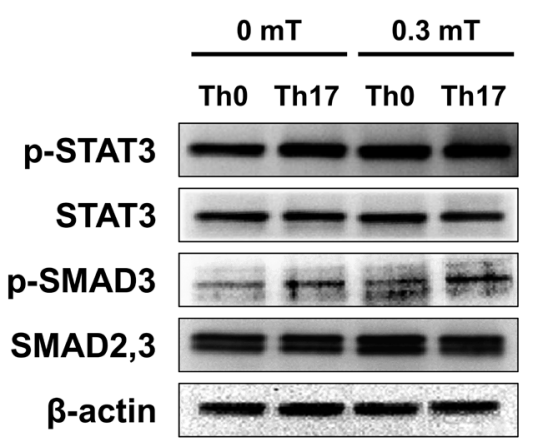

B

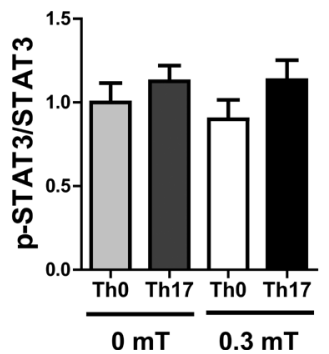

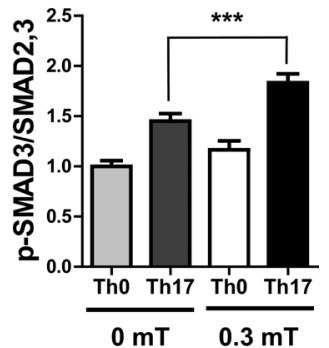

Figure 4. Western blot analysis of signaling molecules in Th17 differentiation. A. $\mathrm{CD} 4^{+} \mathrm{T}$ cells were isolated from mouse splenocytes and were stimulated for $30 \mathrm{~min}$ utes in the presence or absence of Th17-driving conditions, with or without EMF exposure, while being stimulated by anti-CD3 and anti-CD28 antibodies. After harvesting the cells, protein expression levels were determined by Western blot analysis. Beta actin was used as a loading control.

Data are representative of three experiments. B. Expression was normalized against a non-phosphorylated form of STAT3 or SMAD2,3, as appropriate. Asterisks denote significance compared to control. ${ }^{\star * *} p<0.001$.

observed by flow cytometry using Foxp3-GFP transgenic mice. After 72 hours of culture, 1.5 folds increase in Foxp 3 expression $(34.15 \pm 2.2, n=3)$ was observed in $\mathrm{CD}^{+}$cells exposed to EMF under regulatory $\mathrm{T}$ cell-skewing culture conditions, as compared to cells not exposed to EMF (22.26 $\pm 1.5, n=3$ ) (Fig. 5B). Additionally, to confirm that TGF- $\beta$ signaling pathways affected this increase in Treg markers, the levels of p-SMAD3 and SMAD3 signaling molecules were analyzed by Western blot (Fig. 5C and D). Relative phosphorylation level of SMAD3/SMAD3 was increased by 2.1 -folds in cells exposed to EMF $(1.3 \pm 0.3, n=3)$, as compared to cells not exposed to $\operatorname{EMF}(0.6 \pm 0.1, n=3)$ in Treg differentiation conditions. It was found that in Treg differentiation conditions, as in Th17 differentiation conditions (Fig. 4), SMAD3 phosphorylation was increased under the influence of EMF.
A

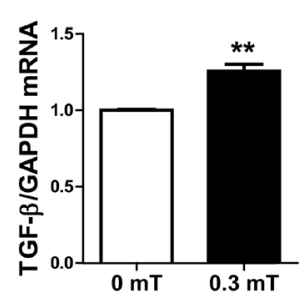

B

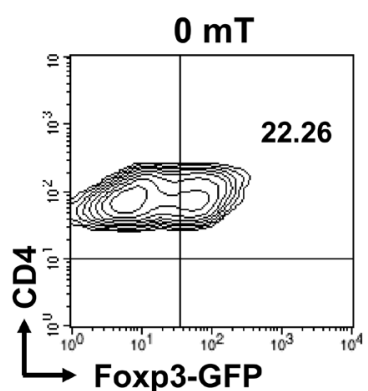

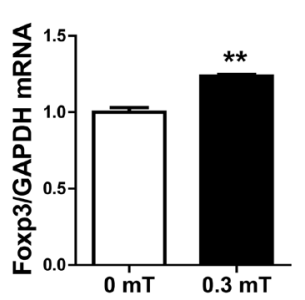

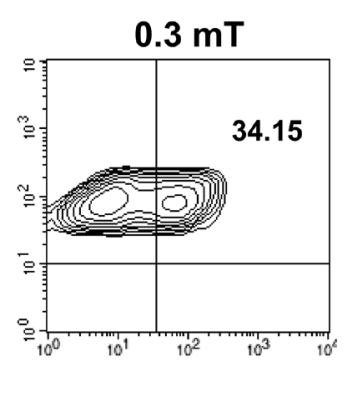

C

D

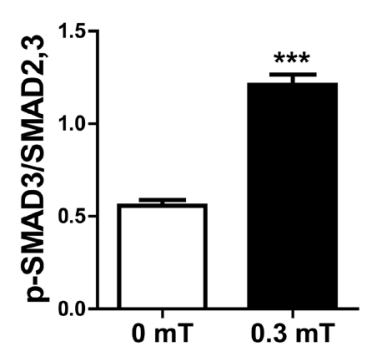

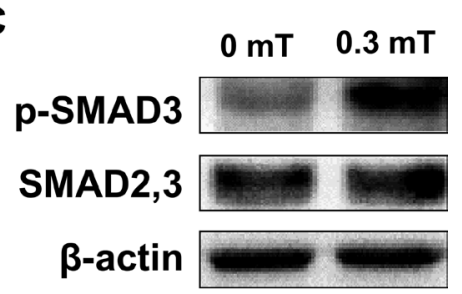

Figure 5. Foxp3 expression is increased after $60 \mathrm{~Hz} 0.3 \mathrm{mT}$ EMF exposure. A. $\mathrm{CD}^{+}{ }^{+} \mathrm{T}$ cells were isolated from mouse splenocytes and cultured in the presence or absence of Treg-driving conditions, with or without EMF exposure, while being stimulated by anti-CD3 and anti-CD28 antibodies. The white bar denotes the control group while the black bar represents the EMF exposed group. Total RNA was extracted and reverse-transcribed for quantitative real-time PCR analysis with appropriate primers. Asterisks denote significance compared to control ${ }^{* *} p<0.01$; ${ }^{* * *} p<0.001$. B. $\mathrm{CD} 4^{+} \mathrm{T}$ cells were isolated from the splenocytes of Foxp3-GFP mice and stimulated in the presence of Treg-driving conditions, with or without EMF exposure, while being stimulated by anti-CD3 and anti$\mathrm{CD} 28$ antibodies. Foxp $3^{+} \mathrm{T}$ cells were detected by flow cytometry. Data are representative of three experiments. C. CD ${ }^{+} \mathrm{T}$ cells were isolated from mouse splenocytes and were stimulated for 6 hours in the presence of Treg-driving conditions, with or without EMF exposure, while being stimulated by anti-CD3 and anti-CD28 antibodies. After harvesting the cells, protein expression levels were determined by western blot analysis. Beta actin was used as a loading control. Data are representative of three experiments. D. Expression was normalized against a non-phosphorylation form of SMAD2,3. Asterisks denote significance compared to control ${ }^{\star * *} p<0.001$. 


\section{Discussion}

EMF and the potential health risk they poses, has been the topic of scientific debate and will continue to be one until more research is undertaken to unravel the effects of exposure in various in vitro and in vivo models. In this study, the effects of $0.3 \mathrm{mT}$ EMF were assessed in murine spleen-derived $\mathrm{CD} 4^{+} \mathrm{T}$ cells. Previous research regarding EMF exposure and T cells have focused on their adherence capabilities in vitro and on the evaluation of T cell subpopulations in a broader scope (Bergier et al. 1990; Cocek et al. 2012). The current study focused specifically on the effect of EMF exposure on differentiation of the Th17 and Treg $\mathrm{CD} 4^{+} \mathrm{T}$ cells subsets, and it was observed that exposure to $60 \mathrm{~Hz} 0.3 \mathrm{mT}$ EMF upregulated the expression of critical markers of the Th17 lineage. IL-17, a cytokine specific to the Th17 subset, has profound pro-inflammatory effects and has been identified as the cause of numerous autoimmune diseases. IL-17 has been shown to directly or indirectly induce destruction of bone and cartilage (Sato et al. 2006), and other IL-17 family members, including IL-17F, have been implicated in inflammatory diseases, autoimmune diseases and cancer (Kolls et al. 2004). The key transcription factor behind the expression of these cytokines and the Th17 subset is the orphan nuclear receptor ROR $\gamma$ t (Ivanov et al. 2006; Lazarevic et al. 2011). Th17 cells are induced by IL- 6 and TGF- $\beta$, and are maintained by IL-23 (Aggarwal et al. 2003; Harrington et al. 2005; Park et al. 2005; Iwakura et al. 2006; McKenzie et al. 2006). The expansion of Th17 cells depends on the existence of IL-23 and IL-23R, as was demonstrated in a study showing that severe EAE induction caused by the transfer of IL-17-producing Th17 cells was expanded with IL-23 (Langrish et al. 2005).

In the present study we showed that the expression of IL$17 \mathrm{~A}$ and IL-17F were upregulated in cells that were exposed to $60 \mathrm{~Hz} 0.3 \mathrm{mT}$ EMF, as was ROR $\gamma \mathrm{t}$ expression. This suggests that EMF exposure amplifies the Th17-driving conditions used in this study. In addition, the production of IL-17A was increased in cells exposed to $60 \mathrm{~Hz} 0.3 \mathrm{mT}$ EMF when they were cultured under Th17-skewing conditions. These results imply that occupational exposure to EMF may exacerbate the inflammation caused by Th17 cells.

It is well known that Th17 cells require at least two cytokines for their induction, namely IL- 6 and TGF- $\beta$ (Bettelli et al. 2006; Mangan et al. 2006). STAT3, which is located downstream of the IL- 6 and IL-23 receptors, has been shown to play a critical role in Th17 cell development, and it was demonstrated that the development of this $\mathrm{T}$ cell lineage was significantly impeded in STAT-3 deficient T cells (X. O. Yang et al. 2007). SMAD2/3 are phosphorylated in response to TGF- $\beta 1$ binding to its receptor, and is critical for the development of suppressive Treg cells and essential for Th17 cell production (Malhotra et al. 2010).
In the present study, it was shown that SMAD3 phosphorylation was increased in response to exposure to $60 \mathrm{~Hz} 0.3$ mT EMF, while STAT3 phosphorylation was comparatively unaffected. The data suggest that higher levels of SMAD3 phosphorylation may be the cause, or at least one of the causes, of the increased production of Th17 effector cytokines observed in this study. The requirement for TGF- $\beta$ in Th17 cell development was demonstrated in a study using an experimental model of multiple sclerosis. TGF- $\beta$ transgenic animals were immunized with the myelin oligodendrocyte glycoprotein $\mathrm{MOG}_{35-55}$ in complete Freund's adjuvant, and these animals developed an exacerbated experimental autoimmune encephalomyelitis (EAE) due to increased numbers of Th17 cells (Bettelli et al. 2006).

Regulatory $\mathrm{T}$ cells are induced from naïve $\mathrm{T}$ cells in the presence of IL- 2 and TGF- $\beta$. SMAD3 was shown to play a part in transducing TGF- $\beta$ signals to generate Foxp $3^{+}$regulatory T cells in a study using SMAD3 mutant mice, where a loss of SMAD3 led to an increased number of activated T cells, as well as inflammation in the colon, which was found to be due to activated T cells attacking gut bacteria (Yang et al. 1999). In the present study, an increase in SMAD3 phosphorylation was observed and the effects of this phosphorylation were confirmed using $\mathrm{CD}^{+}{ }^{+}$cells cultured under Treg-inducing conditions. The mRNA expression of TGF- $\beta$ and Foxp 3 was increased under EMF exposure. In addition, flow cytometric analysis of cultured cells showed that exposure to $60 \mathrm{~Hz} 0.3$ $\mathrm{mT}$ EMF increased the expression of Foxp 3 in $\mathrm{CD} 4{ }^{+}$cells, confirming that increased SMAD3 phosphorylation also affects downstream molecules that generate Foxp $3^{+}$Treg cells.

Collectively, this study aimed to identify the effects of 60 $\mathrm{Hz} 0.3 \mathrm{mT}$ EMF on T cells, and showed that EMF exposure amplifies TGF- $\beta$ signaling and induces subsets of T cells that are related to this signaling pathway.

Acknowledgement. The present research was supported by the Chung-Ang University research grant in 2013 and the Basic Science Research Program through the National Research Foundation of Korea (NRF) funded by the Ministry of Education (NRF-2013R1A1A2009620).

\section{References}

Abbas A. K., Murphy K. M., Sher A. (1996): Functional diversity of helper T lymphocytes. Nature 383, 787-793

http://dx.doi.org/10.1038/383787a0

Aggarwal S., Ghilardi N., Xie M. H., de Sauvage F. J., Gurney A. L. (2003): Interleukin-23 promotes a distinct CD4 T cell activation state characterized by the production of interleukin-17. J. Biol. Chem. 278, 1910-1914 http://dx.doi.org/10.1074/jbc.M207577200

Baldi I., Coureau G., Jaffre A., Gruber A., Ducamp S., Provost D., Lebailly P., Vital A., Loiseau H., Salamon R. (2011): Occupa- 
tional and residential exposure to electromagnetic fields and risk of brain tumors in adults: a case-control study in Gironde France. Int. J. Cancer 129, 1477-1484 http://dx.doi.org/10.1002/ijc.25765

Bennett C. L., Christie J., Ramsdell F., Brunkow M. E., Ferguson P. J., Whitesell L., Kelly T. E., Saulsbury F. T., Chance P. F., Ochs H. D. (2001): The immune dysregulation polyendocrinopathy enteropathy $\mathrm{X}$-linked syndrome (IPEX) is caused by mutations of FOXP3. Nat. Genet. 27, 20-21 http://dx.doi.org/10.1038/83713

Bergier L., Lisiewicz J., Moszczynski P., Rucinska M., Sasiadek U. (1990): Effect of electromagnetic radiation on T-lymphocyte subpopulations and immunoglobulin level in human blood serum after occupational exposure. Med. Pr. 41, 211-215

Bettelli E., Carrier Y., Gao W., Korn T., Strom T. B., Oukka M., Weiner H. L., Kuchroo V. K. (2006): Reciprocal developmental pathways for the generation of pathogenic effector TH17 and regulatory T cells. Nature 441, 235-238 http://dx.doi.org/10.1038/nature04753

Chen W., Jin W., Hardegen N., Lei K. J., Li L., Marinos N., McGrady G., Wahl S. M. (2003): Conversion of peripheral CD4+CD25naive $\mathrm{T}$ cells to $\mathrm{CD} 4+\mathrm{CD} 25+$ regulatory $\mathrm{T}$ cells by TGF-beta induction of transcription factor Foxp3. J. Exp. Med. 198, $1875-1886$ http://dx.doi.org/10.1084/jem.20030152

Chen Y., Langrish C. L., McKenzie B., Joyce-Shaikh B., Stumhofer J. S., McClanahan T., Blumenschein W., Churakovsa T., Low J., Presta L. et al. (2006): Anti-IL-23 therapy inhibits multiple inflammatory pathways and ameliorates autoimmune encephalomyelitis. J. Clin. Invest. 116, 1317-1326 http://dx.doi.org/10.1172/JCI25308

Cocek A., Hahn A., Martonova J., Ambrus M., Dohnalova A., Nedbalova M., Jandova A. (2012): The impact of lower induction values of $50 \mathrm{~Hz}$ external electromagnetic fields on in vitro Tlymphocyte adherence capabilities. Electromagn. Biol. Med. 31, 166-177 http://dx.doi.org/10.3109/15368378.2011.630119

Feychting M., Floderus B., Ahlbom A. (2000): Parental occupational exposure to magnetic fields and childhood cancer (Sweden). Cancer Causes Control 11, 151-156 http://dx.doi.org/10.1023/A:1008922016813

Gately M. K., Renzetti L. M., Magram J., Stern A. S., Adorini L., Gubler U., Presky D. H. (1998): The interleukin-12/interleukin-12-receptor system: role in normal and pathologic immune responses. Annu Rev. Immunol. 16, 495-521 http://dx.doi.org/10.1146/annurev.immunol.16.1.495

Gershon R. K., Kondo K. (1971): Infectious immunological tolerance. Immunology 21, 903-914

Glimcher L. H., Murphy K. M. (2000): Lineage commitment in the immune system: the Thelper lymphocyte grows up. Genes Dev. 14, 1693-1711

Harrington L. E., Hatton R. D., Mangan P. R., Turner H., Murphy T. L., Murphy K. M., Weaver C. T. (2005): Interleukin 17-producing CD4+ effector T cells develop via a lineage distinct from the T helper type 1 and 2 lineages. Nat. Immunol. 6, 1123-1132 http://dx.doi.org/10.1038/ni1254

Hori S., Nomura T., Sakaguchi S. (2003): Control of regulatory T cell development by the transcription factor Foxp3. Science 299, 1057-1061 http://dx.doi.org/10.1126/science.1079490

Ivanov II, McKenzie B. S., Zhou L., Tadokoro C. E., Lepelley A., Lafaille J. J., Cua D. J., Littman D. R. (2006): The orphan nuclear receptor RORgammat directs the differentiation program of proinflammatory IL-17+ T helper cells. Cell 126, 1121-1133 http://dx.doi.org/10.1016/j.cell.2006.07.035

Iwakura Y.,Ishigame H. (2006): The IL-23/IL-17 axis in inflammation. J. Clin. Invest. 116, 1218-1222 http://dx.doi.org/10.1172/JCI28508

Johansen C., Nielsen O. R., Olsen J. H., Schuz J. (2007): Risk for leukaemia and brain and breast cancer among Danish utility workers: a second follow-up. Occup. Environ. Med. 64, 782-784 http://dx.doi.org/10.1136/oem.2006.029116

Kolls J. K., Linden A. (2004): Interleukin-17 family members and inflammation. Immunity 21, 467-476 http://dx.doi.org/10.1016/j.immuni.2004.08.018

Langrish C. L., Chen Y., Blumenschein W. M., Mattson J., Basham B., Sedgwick J. D., McClanahan T., Kastelein R. A., Cua D. J. (2005): IL-23 drives a pathogenic T cell population that induces autoimmune inflammation. J. Exp. Med. 201, 233-240 http://dx.doi.org/10.1084/jem.20041257

Lazarevic V., Chen X., Shim J. H., Hwang E. S., Jang E., Bolm A. N., Oukka M., Kuchroo V. K., Glimcher L. H. (2011): T-bet represses $\mathrm{T}(\mathrm{H}) 17$ differentiation by preventing Runx1-mediated activation of the gene encoding RORgammat. Nat. Immunol. 12, 96-104 http://dx.doi.org/10.1038/ni.1969

Malhotra N., Robertson E., Kang J. (2010): SMAD2 is essential for TGF beta-mediated Th17 cell generation. J. Biol. Chem. 285, 29044-29048 http://dx.doi.org/10.1074/jbc.C110.156745

Mangan P. R., Harrington L. E., O`Quinn D. B., Helms W. S., Bullard D. C., Elson C. O., Hatton R. D., Wahl S. M., Schoeb T. R., Weaver C. T. (2006): Transforming growth factor-beta induces development of the $\mathrm{T}(\mathrm{H}) 17$ lineage. Nature 441, 231-234 http://dx.doi.org/10.1038/nature04754

McKenzie B. S., Kastelein R. A., Cua D. J. (2006): Understanding the IL-23-IL-17 immune pathway. Trends Immunol. 27, $17-23$ http://dx.doi.org/10.1016/j.it.2005.10.003

Norimura T., Imada H., Kunugita N., Yoshida N., Nikaido M. (1993): Effects of strong magnetic fields on cell growth and radiation response of human T-lymphocytes in culture. J. UOEH. 15, 103-112

O‘Garra A., Vieira P. (2003): Twenty-first century Foxp3. Nat. Immunol. 4, 304-306 http://dx.doi.org/10.1038/ni0403-304

Park H., Li Z., Yang X. O., Chang S. H., Nurieva R., Wang Y. H., Wang Y., Hood L., Zhu Z., Tian Q., Dong C. (2005): A distinct lineage of $\mathrm{CD} 4 \mathrm{~T}$ cells regulates tissue inflammation by producing interleukin 17. Nat. Immunol. 6, 1133-1141 http://dx.doi.org/10.1038/ni1261

Paul W. E., Seder R. A. (1994): Lymphocyte responses and cytokines. Cell 76, 241-251 http://dx.doi.org/10.1016/0092-8674(94)90332-8

Sato K., Suematsu A., Okamoto K., Yamaguchi A., Morishita Y., Kadono Y., Tanaka S., Kodama T., Akira S., Iwakura Y., Cua D. 
J., Takayanagi H. (2006): Th17 functions as an osteoclastogenic helper $\mathrm{T}$ cell subset that links $\mathrm{T}$ cell activation and bone destruction. J. Exp. Med. 203, 2673-2682

http://dx.doi.org/10.1084/jem.20061775

Trembleau S., Penna G., Bosi E., Mortara A., Gately M. K., Adorini L. (1995): Interleukin 12 administration induces T helper type 1 cells and accelerates autoimmune diabetes in NOD mice. J. Exp. Med. 181, 817-821 http://dx.doi.org/10.1084/jem.181.2.817

Yang X., Letterio J. J., Lechleider R. J., Chen L., Hayman R. Gu H., Roberts A. B., Deng C. (1999): Targeted disruption of SMAD3 results in impaired mucosal immunity and di- minished T cell responsiveness to TGF-beta. EMBO J. 18, $1280-1291$

http://dx.doi.org/10.1093/emboj/18.5.1280

Yang X. O., Panopoulos A. D., Nurieva R., Chang S. H., Wang D., Watowich S. S., Dong C. (2007): STAT3 regulates cytokinemediated generation of inflammatory helper T cells. J. Biol. Chem. 282, 9358-9363

http://dx.doi.org/10.1074/jbc.C600321200

Received: December 4, 2015

Final version accepted: March 5, 2016

First published online: July 16, 2016 